\title{
Factors associated with prolonged duration of viral clearance in non-severe SARS-CoV-2 patients in Osaka, Japan
}

Emma Nakagawa Hoffman 1,2† , Haruna Kawachi ${ }^{1,2+}$, Atsushi Hirayama1,2, Jingwen Zhang 1,2, Ayumi Murayama', Jun Masui ${ }^{1}$, Satomi Fujita', Yasushi Mori ${ }^{1}$, Takanori Hirayama' ${ }^{1}$, Toshitake Ohara', Rumiko Asada' and Hiroyasu IsO ${ }^{2^{*}}$ (i)

\begin{abstract}
Background: We investigated factors associated with prolonged viral clearance of SARS-CoV-2 among non-severe adult patients in Osaka, Japan. A total of 706 laboratory-confirmed COVID-19 patients were enrolled in this longitudinal observational study between 29 January 2020 and 31 May 2020, across 62 hospitals and three non-hospital recuperation facilities.

Methods: Logistic regression analysis was performed to investigate the factors associated with prolonged (29 days: upper $25 \%$ in duration) viral clearance of SARS-CoV-2. Linear regression analysis was conducted to assess these factors 14 days after symptom onset.

Results: The median duration of viral clearance was 22 days from symptom onset. After adjustment for sex, age, symptoms, comorbidity, and location of recuperation, comorbidities were associated with prolonged duration: (OR, 1.77 [95\% Cl, 1.11-2.82]) for one, (OR, 2.47 [95\% Cl, 1.32-4.61]) for two or more comorbidities. Viral clearance 14 days after symptom onset was 3 days longer for one comorbidity and 4 days longer for two or more comorbidities compared to clearance when there was no comorbidity.
\end{abstract}

Conclusion: The presence of comorbidity was a robust factor associated with a longer duration of viral clearance, extending by 3 to 4 days compared to patients with no comorbidity.

Keywords: COVID-19, Virus shedding, Comorbidity, Longitudinal studies

\section{Introduction}

The outbreak of the coronavirus disease 2019 (COVID$19)$, induced by severe acute respiratory syndrome coronavirus 2 (SARS-CoV-2) and first discovered in Wuhan City, Hubei Province, China, has rapidly become a global

\footnotetext{
*Correspondence: iso@pbhel.med.osaka-u.ac.jp
}

${ }^{\dagger}$ Emma Nakagawa Hoffman and Haruna Kawachi contributed equally to this work.

${ }^{2}$ Public Health, Department of Social Medicine, Graduate School of Medicine, Osaka University, 2-2 Yamadaoka, Suita City, Osaka 565-0871, Japan

Full list of author information is available at the end of the article public health emergency [1]. With an estimated case fatality of 2.2\% [2], the WHO reported a total of over 232 million confirmed cases and 4.7 million deaths worldwide as of September 2021 [3]. In response to this pandemic, researchers have conducted a wide range of studies concerning the epidemiological and clinical characteristics of SARS-CoV-2, mathematical modeling, and health policy [4-6].

While knowledge has accumulated on the clinical course and outcomes of critically ill patients with COVID-19, research on the viral clearance patterns of non-severe patients is scarce. As new cases continue

(c) The Author(s) . Open Access This article is licensed under a Creative Commons Attribution 4.0 International License, which permits use, sharing, adaptation, distribution and reproduction in any medium or format, as long as you give appropriate credit to the original author(s) and the source, provide a link to the Creative Commons licence, and indicate if changes were made. The images or other third party material in this article are included in the article's Creative Commons licence, unless indicated otherwise in a credit line to the material. If material is not included in the article's Creative Commons licence and your intended use is not permitted by statutory regulation or exceeds the permitted use, you will need to obtain permission directly from the copyright holder. To view a copy of this licence, visit http://creativecommons.org/licenses/by/4.0/. The Creative Commons Public Domain Dedication waiver (http://creativecommons.org/ publicdomain/zero/1.0/) applies to the data made available in this article, unless otherwise stated in a credit line to the data. 
to surge in Japan, the number of medical emergencies nationwide that required an ambulance dispatch but had difficulty finding a hospital to accept the patient rose for six consecutive weeks to reach a historic high [7]. Hospitals in Osaka have been at maximum capacity for prolonged periods of time, and the lack of hospital beds remain a serious issue. In order to keep hospitals running efficiently, the admission of patients into hospitals are adjusted by the Infected Persons Follow-up Centre of the Osaka Prefectural Government. Currently, patients are admitted depending on severity of disease; however, data analysis to uncover other indicators to adjust patient admission has not been conducted.

Here, we retrospectively analyzed data relating to 706 patients with non-severe, laboratory-confirmed COVID19 in Osaka and the duration from the onset of disease until consecutive negative detection on reverse transcription polymerase chain reaction (RT-PCR) test of SARS$\mathrm{CoV}-2$. We examined the duration of viral clearance in mild cases of COVID-19 in order to find out what factors are associated with prolonged viral clearance. These findings can be used as supplementary data when coordinating patients for admission and discharge.

To the best of our knowledge, this is the first study conducted to analyze substantial data from patients who recovered at both hospital and non-hospital facilities in Japan. The viral clearance pattern of SARS-CoV-2 has been investigated in limited studies but can be a useful indicator in coordinating patients for admission and discharge.

\section{Methods}

\section{Study design and ethical considerations}

We conducted a longitudinal observational study on COVID-19 patients in Osaka, Japan. Data from the active epidemiological investigation for COVID-19 under the Infectious Diseases Control Law [8] were used in this study, and data was collected between 29 January 2020 and 31 May 2020. Public health nurses working at public health centres throughout Osaka Prefecture collected the data through active epidemiological investigation, such as patient age, sex, comorbidity, date of onset, symptoms, and PCR testing which was collected by telephone or electronic-based worksheets. Informed consent was not required as data analyses were performed in accordance with the Infectious Diseases Control Law; however, all data were anonymized to uphold confidentiality and patient privacy. This study was approved by the ethical committee of Osaka University (T20114).

\section{Study population}

Osaka Prefecture is in the central area of western Japan and covers an area of $1905 \mathrm{~km}^{2}$. Osaka, the third most populous prefecture in Japan, had an estimated population of 8,819,226 as of 1 April 2020 [9]. The first laboratory-confirmed COVID-19 case in Japan was detected on 16 January 2020; thereafter, the first case in Osaka was confirmed on 29 January 2020 . Our study population included all laboratory-confirmed COVID-19 patients in Osaka between 29 January 2020 and 31 May 2020; 1783 patients were treated across 62 hospitals and three nonhospital recuperation facilities as well as homes. The last follow-up date was 30 June 2020. All patients were diagnosed via PCR tests on specimens of sputum, nasopharyngeal swabs, or both, according to laboratory guidance from the National Institute of Infectious Diseases, Japan [9].

We restricted patients involved in this study to those who were classified as 'non-severe' cases throughout inpatient or non-hospital recuperation. Patient severity was defined by categorization provided by the Japanese Ministry of Health, Labour, and Welfare [10] wherein 'mild (with respiratory failure)' indicated difficulty breathing and $\mathrm{SpO}_{2}$ levels $\leq 93 \%$ needing oxygen therapy, and 'severe' indicated being admitted to the ICU or needing mechanical ventilation. 'Non-severe' patients were those who were not categorized in any of these criteria [10]. For asymptomatic patients, the date of specimen collection for a positive test was considered the date of onset, as in the same manner as the guideline principle. As of 31 May 2020, the release criteria for these patients were over $72 \mathrm{~h}$ of symptom clearance and two consecutive negative PCR tests on specimens of either sputum or nasopharyngeal swabs, taken $24 \mathrm{~h}$ apart. In Osaka, nonsevere patients were first admitted to hotel recuperation facilities on 14 April 2020. Admission to non-hospital recuperation facilities was decided by the Infected Persons Follow-up Centre in Osaka Prefecture as requested by the director of public health centres and based on the patients' vital signs, symptoms, age, and comorbidities. The admission criteria for these patients included nonsevere patients, those who maintained independence in activities of daily living (ADLs), and those who had no known active comorbidities requiring medical care.

\section{Measurements}

Clinical characteristics included the following: age, sex, comorbidities (pre-categorized by: diabetes, respiratory disease, coronary heart disease, immunodeficiency, cancer, hypertension, and other), symptoms at the time of admission (pre-categorized by: fever, cough, dyspnea, digestive symptoms, olfactory and taste disorders, fatigue, and other), radiological findings of pneumonia in chest examination of X-ray or CT, location of recuperation, days to admission, and detailed data of PCR testing. The date of symptom onset was defined as the date on 
which the patients reported the first noticeable symptom. Days to admission was defined as the date from symptom onset to date of admission. Information on comorbidities was self-reported and collected based on interviews with public health nurses. At the time of writing, a definitive treatment for the novel coronavirus was still under investigation. Data on pharmaceutical methods of treatment were not obtained in this study, as all patients were considered non-severe and did not require intensive medical intervention such as intubation or ECMO.

\section{Outcomes}

Duration of viral clearance was calculated as the number of days from the date of symptom onset to the date of specimen collection of the first negative PCR test (out of two consecutive tests). Specimens from nasopharyngeal swabs were used in hospitals for PCR tests; sputum specimens were used to test for negativity at hotels or homes. Prolonged duration of viral clearance was defined as the top quartile of the duration and days after 14days of symptom onset.

\section{Statistical analysis}

Continuous variables were presented as median and interquartile range (IQR). Categorical variables were presented as numbers and percentages. Comparisons were determined by Mann-Whitney $U$ test for continuous variables and chi-square test or Fisher's exact test for categorical variables as appropriate. Univariate and multivariate logistic regression analyses were performed to explore the association of sex, age groups, location of recuperation, comorbidities, and symptoms with prolonged duration of viral clearance. Prolonged duration of viral clearance was defined as more than 29 days from symptom onset, the top quartile of the overall duration of viral clearance. Logistic regression analysis was used to calculate odds ratios. Linear regression analysis was also performed to examine the days of viral clearance after 14 days of symptom onset, according to each potential predictor. These analyses were stratified by the location of recuperation, that is, hospitals and non-hospitals. Statistical analyses were performed using Stata version 15.1 (StataCorp, College Station, TX, USA). All $p$ values were two-tailed with $p<0.05$ considered statistically significant.

\section{Results}

\section{Baseline characteristics}

This report describes a cohort of 1783 laboratory-confirmed cases of COVID-19 in Osaka. Figure 1 illustrates the patient selection flowchart for this study. A total of 59 patients aged $<18$ years were excluded from the study; 109 cases were classified as severe or critical; 86 patients died during the study period; and the severity of 11 cases was unknown and therefore excluded. Cases with missing data on dates of PCR testing $(n=520)$, date of illness onset $(n=21)$, and symptoms $(n=271)$ were also

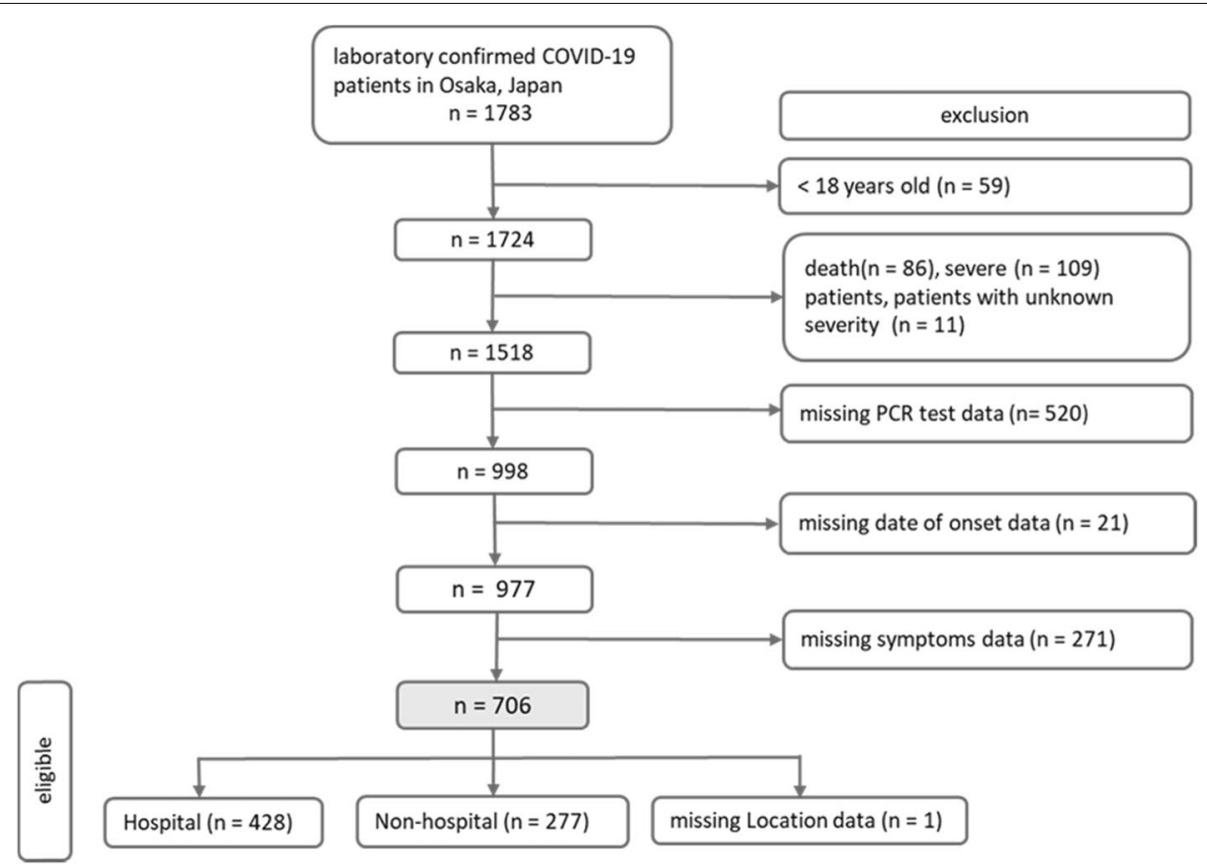

Fig. 1 Flow chart of patient selection 
Table 1 Comparison of clinical characteristics between groups by duration of viral clearance

\begin{tabular}{|c|c|c|c|c|}
\hline & $\begin{array}{l}\text { Overall } \\
(n=706)\end{array}$ & $\begin{array}{l}\text { Prolonged duration } \\
\text { patients } \\
(n=194)\end{array}$ & $\begin{array}{l}\text { Non-prolonged } \\
\text { duration patients } \\
(n=512)\end{array}$ & p value \\
\hline Men, $n(\%)$ & $380(53.8)$ & $107(55.2)$ & $273(53.3)$ & 0.66 \\
\hline Age, median [IQR] & $45[31-58]$ & $47[31-63]$ & $45[31-57]$ & 0.1 \\
\hline \multicolumn{5}{|l|}{ Age categories } \\
\hline$<30, n(\%)$ & $140(19.8)$ & $36(18.6)$ & $104(20.3)$ & \multirow[t]{7}{*}{0.41} \\
\hline $30-39, \underline{n}(\%)$ & $144(20.4)$ & $38(19.6)$ & $106(20.7)$ & \\
\hline $40-49, n(\%)$ & $130(18.4)$ & $33(17.0)$ & $97(19.0)$ & \\
\hline $50-59, n(\%)$ & $131(18.6)$ & $31(16.0)$ & $100(19.5)$ & \\
\hline $60-69, n(\%)$ & $55(7.8)$ & $18(9.3)$ & $37(7.2)$ & \\
\hline $70-79, n(\%)$ & $57(8.1)$ & $21(10.8)$ & $36(7.0)$ & \\
\hline $80+, n(\%)$ & $49(6.9)$ & $17(8.8)$ & $32(6.3)$ & \\
\hline Comorbidity, n (\%) & $199(28.2)$ & $68(35.1)$ & $131(25.6)$ & 0.01 \\
\hline Diabetes, $n(\%)$ & $51(7.2)$ & $19(9.8)$ & $32(6.3)$ & 0.1 \\
\hline Respiratory disease, $n$ (\%) & $51(7.2)$ & $19(9.8)$ & $32(6.3)$ & 0.1 \\
\hline Coronary heart disease, $n(\%)$ & $32(4.5)$ & $12(6.2)$ & $20(3.9)$ & 0.19 \\
\hline Immunodeficiency, n (\%) & $8(1.1)$ & $4(2.1)$ & $4(0.8)$ & 0.15 \\
\hline Cancer, $n(\%)$ & $11(1.6)$ & $3(1.6)$ & $8(1.6)$ & 0.99 \\
\hline Hypertension, $n$ (\%) & $10(1.4)$ & $4(2.1)$ & $6(1.2)$ & 0.37 \\
\hline Others, $n(\%)$ & $103(14.6)$ & $36(18.6)$ & $67(13.1)$ & 0.07 \\
\hline \multicolumn{5}{|l|}{ Number of comorbidities, $n(\%)$} \\
\hline 0 & $511(72.4)$ & $126(65.0)$ & $385(75.2)$ & \multirow[t]{3}{*}{0.02} \\
\hline 1 & $134(19.0)$ & $44(22.7)$ & $90(17.6)$ & \\
\hline $2+$ & $61(8.6)$ & $24(12.4)$ & $37(7.2)$ & \\
\hline \multicolumn{5}{|l|}{ Symptoms } \\
\hline Fever, $n(\%)$ & $458(64.9)$ & $120(61.9)$ & $338(66.0)$ & 0.3 \\
\hline Cough, $n(\%)$ & $377(53.4)$ & $103(53.1)$ & $274(53.5)$ & 0.92 \\
\hline Dyspnea, $n(\%)$ & $164(23.2)$ & $44(22.7)$ & $120(23.4)$ & 0.83 \\
\hline Digestive symptoms, $n(\%)$ & $108(15.3)$ & $30(15.5)$ & $78(15.2)$ & 0.94 \\
\hline Olfactory and taste disorders, $n(\%)$ & $179(25.4)$ & $50(25.8)$ & $129(25.2)$ & 0.88 \\
\hline Fatigue, $n(\%)$ & $269(38.1)$ & $67(34.5)$ & $202(39.5)$ & 0.23 \\
\hline Others, $n(\%)$ & $367(52.0)$ & $94(48.5)$ & $273(53.3)$ & 0.25 \\
\hline Radiological findings (chest examination), $n(\%)$ & $236(33.4)$ & $65(33.5)$ & $171(33.4)$ & 0.95 \\
\hline No findings, $n(\%)$ & $76(10.8)$ & $22(11.3)$ & $54(10.6)$ & \\
\hline Missing, $n(\%)$ & $394(55.8)$ & $107(55.2)$ & $287(56.1)$ & \\
\hline Duration of viral clearance from symptom onset, median [IQR] & 22 [17-29] & $34[31-39]$ & 19 [15-23] & $<0.001$ \\
\hline \multicolumn{5}{|l|}{ Location of recuperation at the time of the (first) PCR test ${ }^{a}$} \\
\hline Hospital, n (\%) & $428(60.7)$ & $100(51.6)$ & $328(64.2)$ & \multirow[t]{2}{*}{0.002} \\
\hline Non-hospital, $n(\%)$ & $277(39.3)$ & $94(48.5)$ & $183(35.8)$ & \\
\hline \multicolumn{5}{|l|}{ Hospitalized patients } \\
\hline Duration from illness onset to admission ${ }^{\mathrm{b}}$, median [IQR] & $7[5-10]$ & $10[7-16]$ & $7[4-9]$ & $<0.001$ \\
\hline Lengths of hospital stay ${ }^{c}$, median [IQR] & $17(12-23)$ & $28(22-33)$ & 15 (10-19) & $<0.001$ \\
\hline
\end{tabular}

${ }^{a}$ One case $(0.1 \%)$ had missing data regarding the location of recuperation $(n=705)$

${ }^{\mathrm{b}}$ Six cases $(0.8 \%)$ had missing data on date of admission (overall $n=422$; prolonged duration patients $n=95$; non-prolonged duration patients $n=327$ )

' Eight cases (1.1\%) of hospitalized patients had missing data on date of admission and/or discharge (overall $n=420$; prolonged duration patients $n=93$; nonprolonged duration patients $n=327$ ) 
excluded. The total number of cases analyzed in the present study was 706 .

The comparison of clinical characteristics is shown in Table 1. Among 706 patients, the median age was 45 years (IQR 31-58); $53.8 \%$ were men. Common underlying concomitant diseases included diabetes (7.2\%), respiratory disease (7.2\%), coronary heart disease (4.5\%), cancer (1.6\%), and hypertension (1.4\%). The major reported symptoms upon admission were fever $\left(>37^{\circ} \mathrm{C}\right.$; $64.9 \%)$, cough $(53.4 \%)$, and fatigue (38.1\%). Upon admission, $33.4 \%$ of patients showed signs of pneumonia on radiological chest examination. Of these patients, $60.7 \%$ were treated at hospitals and $39.3 \%$ were treated at nonhospital facilities.

The median duration of viral clearance was estimated to be 22 days (IQR 17-29) in total patients, 34 days (IQR 31-39) in prolonged patients and 19days (IQR 15-23) in non-prolonged patients (Table 1, Fig. 2). The group with prolonged viral clearance was slightly older (median age 47 years [IQR 31-63]) and had a higher proportion of men (55.2\%) than the group without viral clearance, although this was not a significant difference. The prolonged group had a higher number of comorbidities $(p=0.02)$ and a lower proportion of hospital care than the non-prolonged group (51.6\% vs. $64.2 \%, p=0.002)$. Admission to a treatment facility was delayed in the prolonged group (median days 10 [IQR 7-16]) relative to the non-prolonged group (median days 7 [IQR 4-9]). Figure 3 shows a histogram of the duration of viral clearance among all patients. The overall shape of the distribution is slightly positively skewed to the right. The mode was 22 days, and the maximum value was 62 days. A total of $623(88 \%)$ patients had a viral clearance duration of $\geq 14$ days.

\section{Logistic regression analysis}

The results of univariate and multivariate logistic regression analyses of all patients are presented in Table 2 . Both regression analyses were similar for all variables. Multivariate logistic regression analysis indicated that sex and age were not associated with the risk for prolonged duration. Moreover, patients with any comorbidity were associated with risk compared to those without any comorbidity; the risk increased with the number of comorbidities [one comorbidity (OR 1.77 [95\% CI 1.112.82], $p=0.02$ ); two or more comorbidities (OR 2.47 [95\% CI 1.32-4.61], $p=0.01)]$. Patients who recuperated in hospitals presented with a shorter duration of viral clearance (OR, 0.44 [95\% CI 0.29-0.65], $p<0.001$ ) than those who did not.

The results of the multivariate logistic regression analysis stratified by location are presented in Table 3. Among patients who recuperated in hospitals, increased age was associated with prolonged duration of viral clearance (OR, 1.31 [95\% CI, 1.12-1.52], $p=0.001$ ). Having two or more comorbidities was also associated with prolonged duration of viral clearance compared to having no comorbidity (OR, 2.74 [95\% CI, 1.29-5.83], $p=0.01$ ). In addition, the duration from onset of illness to admission was associated with prolonged duration of viral clearance

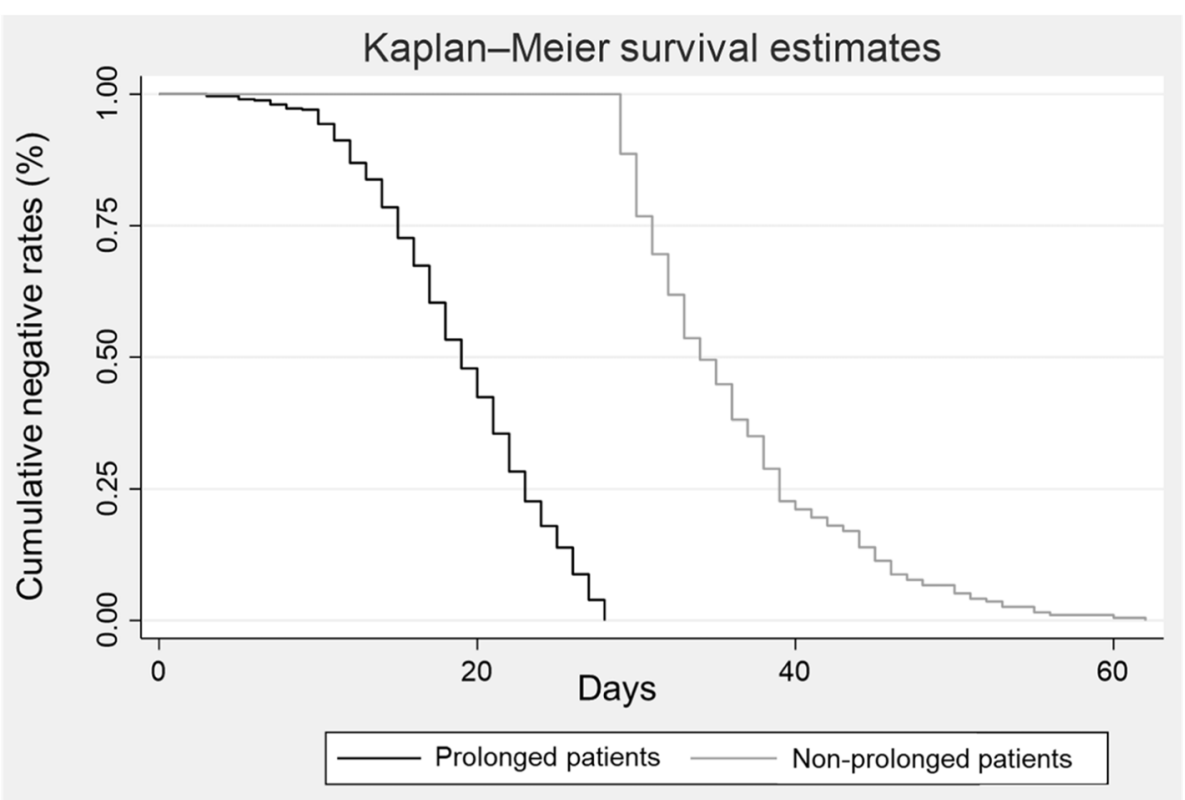

Fig. 2 The cumulative rate of viral clearance in prolonged and non-prolonged patients 


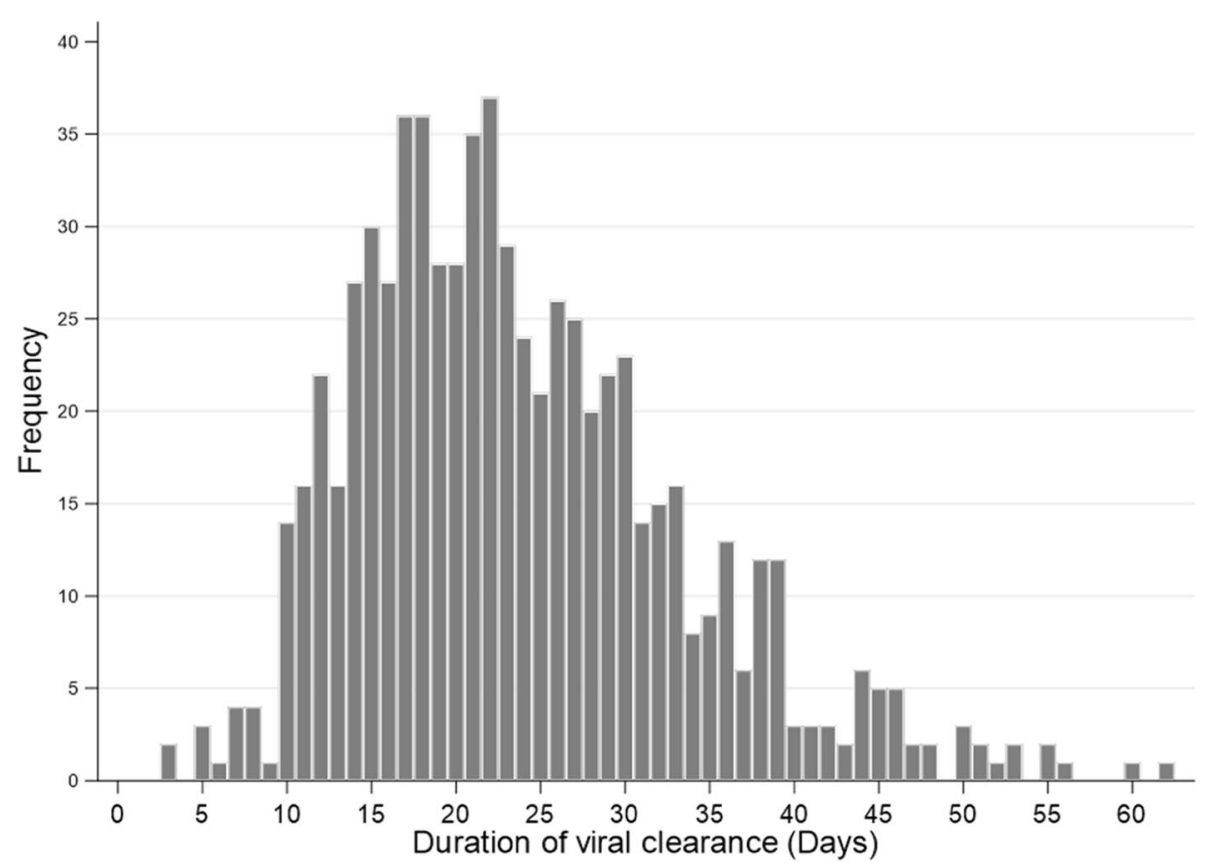

Fig. 3 Histogram of the duration of viral clearance

(OR, 1.18 [95\% CI, 1.13-1.24], $p<0.001$ ). Among patients who recuperated in non-hospital facilities, age and underlying comorbidities were not associated with the risk for prolonged duration of viral clearance.

\section{Linear regression analysis}

Table 4 summarizes the descriptive statistics and results of the multivariate linear regression analysis examining the factors predicting additional days for viral clearance 14 days after symptom onset. The sample comprised 622 patients $(88 \%)$ of 706 eligible cases. The results produced corresponded to those of the logistic regression analysis. Men tended to have shorter prolonged days among hospitalized patients and longer prolonged days among non-hospitalized patients. Increased age tended to be associated with longer prolonged days among hospitalized patients and shorter prolonged days among nonhospitalized patients. There was a positive association between the number of comorbidities and prolonged duration of viral clearance among all patients. Patients with one comorbidity experienced 3 days longer duration; those with two or more comorbidities experienced 4 days longer duration when compared to those with no comorbidity ( $p=0.001$ and $p=0.002$, respectively). For both of the hospitalized and non-hospitalized patients, the prolonged days were slightly shorter among patients with one comorbidity and slightly longer among those with two or more comorbidities, as compared to those with no comorbidity.

\section{Discussion}

We observed that comorbidities were associated with prolonged duration: (OR 1.77 [95\% CI, 1.11-2.82]) for one, (OR 2.47 [95\% CI, 1.32-4.61]) for two or more comorbidities. Viral clearance 14 days after symptom onset was 3 days longer for one comorbidity and 4 days longer for two or more comorbidities compared to clearance when there was no comorbidity. The number of comorbidities was significantly associated with prolonged duration in a dose-response manner.

An increasing number of studies have illustrated the relationship between COVID-19 comorbidity and disease severity [11-13]. For example, diabetes, a prevalent comorbidity in our study, is characterized by an exaggerated pro-inflammatory cytokine response, notably interleukin-1 (IL), IL-6, and tumor necrosis factor (TNF)- $\alpha$. Immunological studies suggest that in the absence of appropriate immune stimulation, a cytokine response may be further exaggerated in order to counter the stimulus, as seen in patients with COVID-19 [14, 15]. Additionally, studies on the relationship between infectious diseases and host metabolic processes have speculated that metabolic programming is an essential regulator of inflammatory responses. Physiologic abnormalities, such as type 2 diabetes and hypertension, hinder the recovery of COVID-19 [16].

In our study, delayed hospitalization was associated with prolonged duration of viral clearance. At the time of study, patients could only be discharged from 
Table 2 Logistic regression analysis for factors associated with prolonged duration of viral clearance among all patients $(n=706)$

\begin{tabular}{|c|c|c|c|c|c|c|c|}
\hline \multirow[b]{2}{*}{ Variables (total number $(n)$ ) } & \multirow{2}{*}{$\begin{array}{l}\text { Prolonged } \\
\text { duration patients } \\
(n=194) \\
n(\%)\end{array}$} & \multicolumn{3}{|c|}{ Univariate logistic regression } & \multicolumn{3}{|c|}{ Multivariate logistic regression ${ }^{\mathrm{a}, \mathrm{c}}$} \\
\hline & & OR & $95 \% \mathrm{Cl}$ & $p$ value & OR & $95 \% \mathrm{Cl}$ & $p$ value \\
\hline \multicolumn{8}{|l|}{ Sex } \\
\hline Women $(n=326)$ & $87(26.7)$ & ref. & & & ref. & & \\
\hline Men $(n=380)$ & $107(28.2)$ & 1.08 & $0.77-1.5$ & 0.66 & 1.05 & $0.74-1.49$ & 0.78 \\
\hline Age: 10 years old increment & & 1.08 & $0.99-1.19$ & 0.08 & 1.09 & $0.97-1.21$ & 0.13 \\
\hline Comorbidity $(n=199)$ & $68(34.2)$ & 1.57 & $1.01-2.24$ & 0.01 & & & \\
\hline Diabetes $(n=51)$ & $19(37.3)$ & 1.63 & $0.90-2.95$ & 0.11 & & & \\
\hline Respiratory disease $(n=51)$ & $19(37.3)$ & 1.63 & $0.90-2.95$ & 0.11 & & & \\
\hline Coronary heart disease $(n=32)$ & $12(37.5)$ & 1.62 & $0.78-3.38$ & 0.20 & & & \\
\hline Immunodeficiency $(n=8)$ & $4(50.0)$ & 2.67 & $0.66-10.8$ & 0.17 & & & \\
\hline Cancer $(n=11)$ & $3(27.3)$ & 0.99 & $0.26-3.77$ & 0.99 & & & \\
\hline Hypertension $(n=10)$ & $4(40.0)$ & 1.78 & $0.50-6.36$ & 0.38 & & & \\
\hline Others $(n=103)$ & $36(35.0)$ & 1.51 & $0.97-2.36$ & 0.07 & & & \\
\hline \multicolumn{8}{|l|}{ Number of comorbidities } \\
\hline $0(n=511)$ & $126(24.7)$ & ref. & & & ref. & & \\
\hline $1(n=134)$ & $44(32.8)$ & 1.49 & $0.99-2.26$ & 0.06 & 1.77 & $1.11-2.82$ & 0.02 \\
\hline $2+(n=61)$ & $24(39.3)$ & 1.98 & $1.14-3.44$ & 0.02 & 2.47 & $1.32-4.61$ & 0.01 \\
\hline  & & 1.13 & $1.09-1.17$ & $<0.001$ & & & \\
\hline \multicolumn{8}{|l|}{ Symptoms } \\
\hline Fever $(n=458)$ & $120(26.2)$ & 0.83 & $0.59-1.18$ & 0.3 & 0.96 & $0.65-1.42$ & 0.85 \\
\hline Cough $(n=377)$ & $103(27.3)$ & 0.98 & $0.71-1.37$ & 0.92 & 1.07 & $0.74-1.53$ & 0.71 \\
\hline Dyspnea $(n=164)$ & $44(26.8)$ & 0.96 & $0.65-1.42$ & 0.83 & 1.06 & $0.69-1.62$ & 0.80 \\
\hline Digestive symptoms $(n=108)$ & $30(27.8)$ & 1.02 & $0.64-1.61$ & 0.94 & 1.10 & $0.68-1.77$ & 0.71 \\
\hline Olfactory and taste disorders $(n=179)$ & $50(27.9)$ & 1.03 & $0.71-1.51$ & 0.88 & 1.03 & $0.69-1.55$ & 0.88 \\
\hline Fatigue $(n=269)$ & $67(24.9)$ & 0.81 & $0.57-1.14$ & 0.23 & 0.75 & $0.51-1.09$ & 0.13 \\
\hline Other $(n=367)$ & $94(25.6)$ & 0.82 & $0.59-1.15$ & 0.25 & 0.84 & $0.59-1.21$ & 0.36 \\
\hline \multicolumn{8}{|l|}{ Location of recuperation ${ }^{b}$} \\
\hline Non-hospital $(n=277)$ & $94(33.9)$ & ref. & & & ref. & & \\
\hline Hospital $(n=428)$ & $100(23.4)$ & 0.59 & $0.42-0.83$ & 0.002 & 0.44 & $0.29-0.65$ & $<0.001$ \\
\hline
\end{tabular}

${ }^{a}$ Six cases (1.4\%) had missing data on date of admission or location of recuperation. $(n=422)$

${ }^{b}$ One case $(0.1 \%)$ had missing data regarding the location of recuperation. $(n=705)$

'Multivariate logistic regression adjusted for sex, age (10years old increment), number of comorbidities, symptoms (cough, dyspnea, digestive symptoms, olfactory and taste disorders, fatigue, other symptoms), and location of recuperation

OR adjusted odds ratio, $95 \% \mathrm{Cl}$ 95\% confidence interval, ref reference

hospitals after testing negative on two consecutive PCR tests. Therefore, delayed hospitalization led to prolonged duration of hospitalization. Although discharge guidelines as of September 2021 do not require consecutive negative PCR tests, delayed hospitalization remains an issue. Ambulance dispatchers have had difficulty finding a hospital to accept the patients and hospitals in Osaka have been at maximum capacity for prolonged periods of time. In order to keep hospitals running efficiently, the findings of this study can be used as supplementary data or used as indicators when adjusting patients for hospitalization.
In our study, the median duration of viral clearance was 22 days from symptom onset. In a Chinese study of 99 patients (median age 54years [IQR 43-63], 58.4\% male), a median SARS-CoV-2 excretion period of 15 days was reported [17]. Furthermore, another Chinese study of 113 patients (median age 51 years [IQR 43-63], 58.4\% male) reported a median duration of SARS-CoV-2 RNA detection of 17 days [18]. These Chinese studies were conducted with a retrospective 1-month observation period in hospitals under repeated measurements, regardless of the patient's symptoms. Additionally, an Italian study of 1162 patients (median age 60.7 [SD 16.3]) 


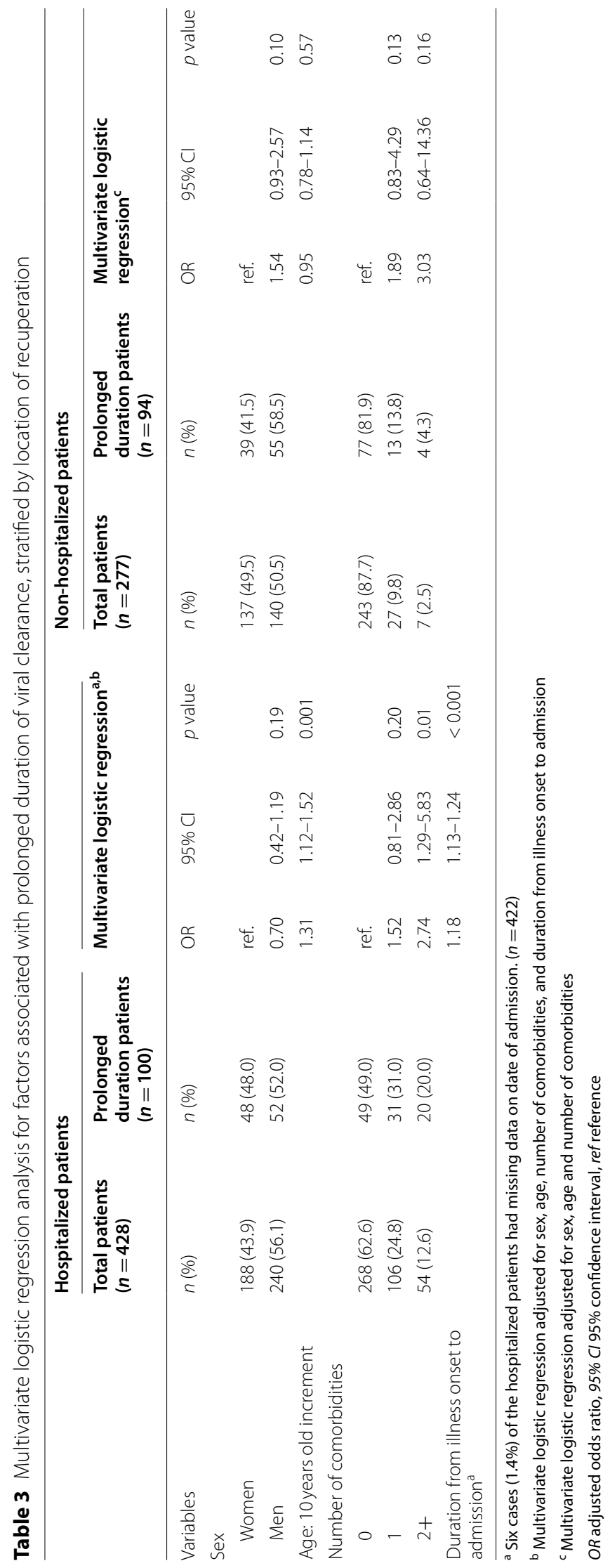


Table 4 Multivariate linear regression analysis for variables predicting prolonged days of viral clearance 14 days after symptom onset

\begin{tabular}{|c|c|c|c|c|c|c|}
\hline \multirow[b]{2}{*}{ Variables } & \multicolumn{2}{|c|}{ All patients $\left(n=622^{\mathrm{a}}\right)$} & \multicolumn{2}{|c|}{ Hospitalized patients $\left(n=359^{c}\right)$} & \multicolumn{2}{|c|}{$\begin{array}{l}\text { Non-hospitalized patients } \\
(n=257)\end{array}$} \\
\hline & Adjusted $^{\mathrm{b}}$ & & Adjusted $^{c, d}$ & & Adjusted $^{e}$ & \\
\hline & $\beta$ coefficient & $p$ value & $\beta$ coefficient & $p$ value & $\beta$ coefficient & $p$ value \\
\hline Men & 0.22 & 0.76 & -1.53 & 0.08 & 2.54 & 0.01 \\
\hline Age: 10 years old increment & 0.04 & 0.87 & 0.44 & 0.08 & -0.56 & 0.15 \\
\hline \multicolumn{7}{|l|}{ Number of comorbidities } \\
\hline 0 & ref. & - & ref. & - & ref. & - \\
\hline 1 & 3.15 & 0.001 & 2.98 & 0.01 & 2.43 & 0.15 \\
\hline $2+$ & 4.17 & 0.002 & 4.76 & 0.001 & 4.74 & 0.17 \\
\hline Recuperation at hospital $^{a}$ & -2.44 & 0.002 & - & - & - & - \\
\hline $\begin{array}{l}\text { Duration from illness onset to } \\
\text { admission }^{d}\end{array}$ & - & - & 0.6 & $<0.001$ & - & - \\
\hline
\end{tabular}

${ }^{a}$ One $(0.2 \%)$ case of all patients had missing data on location of recuperation. $(n=622)$

${ }^{\mathrm{b}}$ Multiple linear regression adjusted for sex, age, number of comorbidities, and location of recuperation

' Six (1.6\%) cases of hospitalized patients had missing data on date of admission. ( $n=359)$

${ }^{\mathrm{d}}$ Multiple linear regression adjusted for sex, age, number of comorbidities, and duration from illness onset to admission

e Multiple linear regression adjusted for sex, age and number of comorbidities

reported a median duration of viral clearance of 36 days [19]. In that study, PCRs were tested at 7-day intervals, which may have resulted in a longer duration of viral clearance. Our findings were similar to those of a small Japanese study of 63 patients treated at hospitals in Nara Prefecture (median age 47 [SD 19.9]). This study reported a viral clearance period of 20 days [20].

\section{Limitations}

Our study has several limitations. As this was a multicentered study, the timing of the negative PCR tests differed between hospitals and hotels. PCR tests for negativity were conducted at frequent intervals in hospitals compared to non-hospital facilities, as more medical staff were available on site. Therefore, the location was stratified; statistical analysis was conducted. This study was conducted in real-world practice and therefore the results of this analysis should be carefully interpreted, as many patients were excluded from the analysis due to missing PCR test results $(n=520)$ and symptom onset $(n=271)$. Supplementary Table 1 shows a comparison of the clinical characteristics between the excluded and non-excluded groups. Compared with the excluded group, the eligible group had a lower proportion of young people under 30 years, a higher proportion of people with comorbidities, and a higher proportion of individuals who recuperated in a hospital. This may have influenced the duration of viral clearance in the eligible group. Furthermore, a limitation of this study was that information on comorbidities was self-reported resulting in the possibility of misclassification. Symptom data was only collected upon admission. Because the duration between onset and admission differed between study subjects, some symptoms may have appeared after admission. Another limitation of this study was the absence of data on viral load. Although the use of sensitive PCR methods offers value from a diagnostic viewpoint, the presence of nucleic acids alone cannot be used to define viral RNA shedding or infectivity. For many viral diseases, such as SARS-CoV and MERS-CoV, it is known that viruses can be detected during testing long after the disappearance of the infectious virus [21, 22]. Wolfel and colleagues reported seroconversion occurred in $50 \%$ of patients (out of 14 patients) after 7 days of symptom onset, as live virus could no longer be cultured [23]. At the time of data collection until May 2020, the global standard used for deisolation and discharge policies was testing negative on two consecutive PCR tests, with each test more than $24 \mathrm{~h}$ apart. As knowledge on the infectivity of SARS-CoV-2 has accumulated, global standards will change. The CDC currently recommends the de-isolation of non-severe patients after 10 days if no symptoms are reported [24]. Although viral culture is a beneficial method for evaluating viral infectivity, such data are generally unavailable in clinical practice because of their low sensitivity and long turn-around time for virus detection [25]. Insightful epidemiological analyses may produce sufficient knowledge to improve public health guidelines without the detection of specific agents at the microscopic level.

\section{Conclusion}

Our study presented the patient characteristics and analyzed the viral clearance patterns of nonsevere patients who recovered at both hospital and 
non-hospital facilities. We found that comorbidity was a significant factor associated with prolonged duration of viral clearance, extending by 3 to 4 days compared to when there was no comorbidity. Our findings add to the limited literature on the viral clearance patterns of SARS-CoV-2. Gaining a better understanding of the significance of viral clearance and infectiousness is important for both clinical practice and public policy. Since the effective medicines have not yet been developed for COVID-19, and hospitals continue to operate at maximum capacity, clarifying the viral clearance period for new mutant virus is essential. In this study, we determined underlying comorbidity can be used as an indicator when adjusting patients for hospitalization. What remains critical is incorporating the best evidence of viral clearance and infective risk into routine care practices to reduce excess intervention and fear among healthcare workers and the general population.

\begin{abstract}
Abbreviations
COVID-19: Coronavirus disease of 2019; OR: Odds ratio; $95 \%$ Cl: 95\% confidence interval; SARS-CoV-2: Severe acute respiratory syndrome coronavirus 2; RT-PCR: Reverse transcription polymerase chain reaction; ADLs: Activities of daily living; IQR: Interquartile range; IL: Interleukin; TNF: Tumor necrosis factor.
\end{abstract}

\section{Supplementary Information}

The online version contains supplementary material available at https://doi. org/10.1186/s12199-021-01035-y.

Additional file 1: Supplementary Table 1 Comparison of clinical characteristics between non-severe adult population. Supplementary Table 2 Comparison of clinical characteristics by location of recuperation

\section{Acknowledgements}

The authors wish to thank Professors Tomotaka Sobue and Kazunori Tomono for providing valuable comments on this manuscript.

\section{Authors' contributions \\ ENH and HK conceived the study design. ENH and HK drafted the manu- script. AH, JZ, AM, JM, SF, and YM collected the data and performed statistical analyses. $A H, J M, T H$, and TO input their clinical expertise and critically revised the manuscript. All authors approved the version for publication. IH and RA supervised the whole manuscript. All authors read and approved the final manuscript.}

\section{Funding}

Not applicable.

\section{Availability of data and materials}

The data analyzed in this study are not publicly available.

\section{Declarations}

This study was approved by the ethical committee of Osaka University (T20114).Consent for publication

Not applicable.

\section{Competing interests}

All authors declare that they have no competing interests.

\section{Author details}

'Osaka Prefectural Government, Department of Public Health and Medical Affairs, 1-2 Otemae, Chuo-ku, Osaka 540-8570, Japan. ${ }^{2}$ Public Health, Department of Social Medicine, Graduate School of Medicine, Osaka University, 2-2 Yamadaoka, Suita City, Osaka 565-0871, Japan.

Received: 26 August 2021 Accepted: 12 November 2021

Published online: 06 December 2021

\section{References}

1. Lu H, Stratton CW, Tang YW. Outbreak of pneumonia of unknown etiology in Wuhan, China: the mystery and the miracle. J Med Virol. 2020;92(4):401-2.

2. Russell TW, Hellewell J, Jarvis Cl, van Zandvoort K, Abbott S, Ratnayake $R$ et al. Estimating the infection and case fatality ratio for coronavirus disease (COVID-19) using age-adjusted data from the outbreak on the Diamond Princess cruise ship, February 2020. Euro Surveill 2020;25(12).

3. WHO. Coronavirus disease (COVID-19). World Health Organization. https://covid19.who.int/.4. Young BE, Ong SWX, Kalimuddin S, Low JG, Tan SY, Loh J et al. Epidemiologic features and clinical course of patients infected with SARS-CoV-2 in Singapore. JAMA 2020;323(15):1488-1494.

4. Martinez-Portilla RJ, Goncé A, Hawkins-Villarreal A, Figueras F. A Spanishtranslated clinical algorithm for management of suspected SARS-CoV-2 infection in pregnant women. Lancet Infect Dis. 2020;20(6):655.

5. Wang X, Zhang X, He J. Challenges to the system of reserve medical supplies for public health emergencies: reflections on the outbreak of the severe acute respiratory syndrome coronavirus 2 (SARS-CoV-2) epidemic in China. BioSci Trends. 2020;14(1):3-8.

6. Fire and Disaster Management Agency. Results of the survey of the situation regarding difficult emergency transport cases from each fire department [in Japanese]; 2021. https://www.fdma.go.jp/disaster/coron avirus/items/coronavirus_kekka.pdf

7. National Institute of Infectious Diseases. Manual for active epidemiological surveillance of patients with novel coronavirus infection (provisional version); 2020. https://www.niid.go.jp/niid/en/2019-ncov-e/2484-idsc/ 9472-2019-ncov-02-en.html

8. Osaka Prefectural Government. Statistic information of Osaka. Osaka Prefectural Government. Stat Inf Osaka. [in Japanese]. http://www.pref. osaka.lg.jp/toukei/jinkou/ 2020.

9. The Japanese Ministry of Health, Labour and Welfare. Clinical management of patients with COVID-19: a guide for front-line healthcare workers version 2 [in Japanese]. 2020. https://www.mhlw.go.jp/content/00063 1552.pdf.

10. Guan WJ, Liang WH, Zhao Y, Liang HR, Chen ZS, Li YM, Liu XQ, Chen RC, Tang CL, Wang T, Ou CQ, Li L, Chen PY, Sang L, Wang W, Li JF, Li CC, Ou LM, Cheng B, Xiong S, Ni ZY, Xiang J, Hu Y, Liu L, Shan H, Lei CL, Peng YX, Wei L, Liu Y, Hu YH, Peng P, Wang JM, Liu JY, Chen Z, Li G, Zheng ZJ, Qiu SQ, Luo J, Ye CJ, Zhu SY, Cheng LL, Ye F, Li SY, Zheng JP, Zhang NF, Zhong NS, He JX, \& China Medical Treatment Expert Group for COVID-19. Comorbidity and its impact on 1590 patients with COVID-19 in China: a nationwide analysis. Eur Respir J 2020;55(5).

11. Du RH, Liang LR, Yang CQ, Wang W, Cao TZ, Li M, et al. Predictors of mortality for patients with COVID-19 pneumonia caused by SARS-CoV-2: a prospective cohort study. Eur Respir J 2020;55(5).

12. Zaki N, Alashwal H, Ibrahim S. Association of hypertension, diabetes, stroke, cancer, kidney disease, and high-cholesterol with COVID-19 disease severity and fatality: a systematic review. Diabetes Metab Syndr. 2020;14(5):1133-42.

13. Geerlings SE, Hoepelman Al. Immune dysfunction in patients with diabetes mellitus (DM). FEMS Immunol Med Microbiol. 1999;26(3-4):259-65.

14. Fang L, Karakiulakis G, Roth M. Are patients with hypertension and diabetes mellitus at increased risk for COVID-19 infection? Lancet Respir Med. 2020;8(4):e21.

16. Ayres JS. A metabolic handbook for the COVID-19 pandemic. Nat Metab. 2020;2(7):572-85.

17. Shi D, Wu W, Wang Q, Xu K, Xie J, Wu J, et al. Clinical characteristics and factors associated with long-term viral excretion in patients with severe 
acute respiratory syndrome coronavirus 2 infection: a single-center 28-day study. J Infect Dis. 2020;222(6):910-8.

18. Xu K, Chen Y, Yuan J, Yi P, Ding C, Wu W, et al. Factors associated with prolonged viral RNA shedding in patients with coronavirus disease 2019 (COVID-19). Clin Infect Dis. 2020;71(15):799-806.

19. Vena A, Taramasso L, Di Biagio A, Mikulska M, Dentone C, De Maria A, et al. \& GECOVID study group. Prevalence and clinical significance of persistent viral shedding in hospitalized adult patients with SARS-CoV-2 infection: a prospective observational study. Infect Dis Ther. 2021:10(1):387-98.

20. Hirai N, Nishioka Y, Sekine T, Nishihara Y, Okuda N, Nishimura T, et al. Factors associated with viral clearance periods from patients with COVID19: a retrospective observational cohort study. J Infect Chemother. 2021:27(6):864-8.

21. Chan KH, Poon LL, Cheng VC, Guan Y, Hung IF, Kong J, et al. Detection of SARS coronavirus in patients with suspected SARS. Emerg Infect Dis. 2004;10(2):294-9.

22. Oh MD, Park WB, Choe PG, Choi SJ, Kim Jl, Chae J, et al. Viral load kinetics of mers coronavirus infection. N Engl J Med. 2016;375(13):1303-5.
23. Wölfel R, Corman VM, Guggemos W, Seilmaier M, Zange S, Müller MA, et al. Virological assessment of hospitalized patients with COVID-2019. Nature. 2020;581(7809):465-9.

24. Centers for Disease Control and Prevention. 2020. Options to reduce quarantine for contacts of persons with SARS-CoV-2; 2020. https://www. cdc.gov/coronavirus/2019-ncov/more/scientific-brief-options-to-reducequarantine.htm|\#: :text=CDC\%20currently\%20recommends\%20a\% 20quarantine,been\%20reported\%20during\%20daily\%20monitoring.

25. Charlton CL, Babady E, Ginocchio CC, Hatchette TF, Jerris RC, Li $Y$, et al. Practical guidance for clinical microbiology laboratories: viruses causing acute respiratory tract infections. Clin Microbiol Rev. 2019;32(1):e00042-18.

\section{Publisher's Note}

Springer Nature remains neutral with regard to jurisdictional claims in published maps and institutional affiliations.
Ready to submit your research? Choose BMC and benefit from:

- fast, convenient online submission

- thorough peer review by experienced researchers in your field

- rapid publication on acceptance

- support for research data, including large and complex data types

- gold Open Access which fosters wider collaboration and increased citations

- maximum visibility for your research: over $100 \mathrm{M}$ website views per year

At BMC, research is always in progress.

Learn more biomedcentral.com/submissions 